OPEN ACCESS

Edited by:

Kazuya Iwabuchi,

Kitasato University School of

Medicine, Japan

Reviewed by:

Paolo Dellabona,

San Raffaele Scientific Institute

(IRCCS), Italy

Hyun Park,

National Cancer Institute (NCl),

United States

${ }^{*}$ Correspondence:

Nyambayar Dashtsoodo nyambayar.dashtsoodo/@tum.de Marc Schmidt-Supprian marc.supprian@tum.de

Specialty section: This article was submitted to

T Cell Biology,

a section of the journal

Frontiers in Immunology

Received: 31 January 2019 Accepted: 01 April 2019 Published: 26 April 2019

Citation: Dashtsoodol N, Bortoluzzi S and Schmidt-Supprian M (2019) T Cell Receptor Expression Timing and Signal Strength in the Functional Differentiation of Invariant Natural Killer

T Cells. Front. Immunol. 10:841. doi: 10.3389/fimmu.2019.00841

\section{T Cell Receptor Expression Timing and Signal Strength in the Functional Differentiation of Invariant Natural Killer T Cells}

\author{
Nyambayar Dashtsoodol ${ }^{1,2 *}$, Sabrina Bortoluzzi ${ }^{1}$ and Marc Schmidt-Supprian ${ }^{1 *}$ \\ 1 Department of Hematology and Medical Oncology, Klinikum rechts der Isar and TranslaTUM Cancer Center, Technische \\ Universität München, München, Germany, ${ }^{2}$ Department of Microbiology and Immunology, School of Biomedicine, Mongolian \\ National University of Medical Sciences, Ulaanbaatar, Mongolia
}

The CD1d-restricted Va14 invariant NKT (iNKT) cell lineage in mice ( $V_{\alpha 2} 24$ in humans) represents an evolutionary conserved innate-like immune cell type that recognizes glycolipid antigens. Because of their unique ability to promptly secrete copious amounts of both pro-inflammatory and anti-inflammatory cytokines, typically produced by different $T$ helper cell types, iNKT cells are implicated in the regulation of various pathologic conditions such as infection, allergy, autoimmune disease, maintenance of transplantation tolerance, and cancer. This striking multifaceted role in immune regulation is correlated with the presence of multiple functionally distinct iNKT cell subsets that can be distinguished based on the expression of characteristic surface markers and transcription factors. However, to date it, remains largely unresolved how this puzzling diversity of iNKT cell functional subsets emerges and what factors dictate the type of effector cell differentiation during the thymic differentiation considering the mono-specific nature of their $T$ cell receptor (TCR) and their selecting molecule CD1d. Here, we summarize recent findings focusing on the role of TCR-mediated signaling and discuss possible mechanisms that may influence the sub-lineage choice of iNKT cells.

Keywords: NKT, CD1d, lymphocyte, development, functional subset, thymus, T cell receptor, developmental pathway

\section{INTRODUCTION}

Innate-like $\mathrm{T}$ lymphocytes are a special group of immune cells assumed to play important immunoregulatory functions by linking and orchestrating the functions of multiple cell types of the innate and adaptive arms of the immune system $(1,2)$.

The invariant NKT (iNKT) cells, often referred to as Va14 iNKT cells in mice (Va24 in humans), represent an evolutionary conserved innate-like immune cell type characterized by the expression of a unique semi-invariant T cell receptor (TCR). This TCR is composed of a single invariant $\alpha$-chain V $\alpha 14 \mathrm{~J} \alpha 18$ (encoded by Trav11Traj18) usually paired with a limited range of TCR $\beta$-chains, mostly V $\beta 8.2$, V $\beta 7$, or V $\beta 2$ (TRBV13-2, TRBV29, and TRBV1), in mice and a V $\alpha 24 \mathrm{~J} \alpha 18$ TCR $\alpha$-chain (encoded by Trav10Traj18) paired exclusively with V $\beta 11$ (TRBV25) in humans. As opposed to the conventional peptide-recognizing CD8 T cells or CD4 T cells, iNKT cells are specialized in recognizing glycolipid antigens including alpha-galactosylceramide $(\alpha$-GalCer) presented by the monomorphic MHC class I-like CD1d molecule (3-7). Owing to the 
early availability of specific analysis tools such as CD1d tetramers $(8,9)$, as well as various gene-manipulated mouse models that either lack (10-17) or overexpress (18-22) these cells, to date iNKT cells represent the best-studied innate-like $\mathrm{T}$ lymphocyte lineage.

The hallmark feature of iNKT cells is their unique ability to secrete very large amounts of both pro-inflammatory and anti-inflammatory cytokines, typically produced by $\mathrm{T}$ helper cell type $1\left(\mathrm{~T}_{\mathrm{H}} 1\right), \mathrm{T}_{\mathrm{H}} 2$, and $\mathrm{T}_{\mathrm{H}} 17$ cells. Cytokine secretion occurs rapidly upon activation and does not require clonal expansion or antigenic priming. Therefore, in line with their innate-like ability to robustly produce multiple immunoregulatory cytokines, iNKT cells were implicated in the regulation of various pathologic conditions such as infection, allergy, autoimmune disease, maintenance of transplantation tolerance, and cancer $(23,24)$. Because of this unique feature to elicit protective, regulatory, and pathogenic functions, it was proposed that iNKT cells constitute a heterogenous population. In fact, recent publications have demonstrated the presence of multiple functionally distinct subsets with discrete cytokine polarization within the iNKT cell lineage that can be distinguished based on the expression of characteristic surface markers and transcription factors (Table 1) $(25,26)$. The differentiation of iNKT cells proceeds within highly restricted context dictated by the recognition of self-glycolipids on CD1d by their semi-invariant TCR. To date, it remains largely unresolved how this puzzling diversity of iNKT cell functional subsets emerges and what factors dictate the type of effector cell differentiation during thymic differentiation.

As a number of excellent reviews have extensively covered advances in the iNKT cell developmental field (27, 30-34), in this mini-review, we attempted to summarize recent findings focusing on the role of TCR-mediated signaling and discuss possible mechanisms that may influence the sub-lineage choice of iNKT cells. A better understanding of the mechanisms underlying the differentiation of iNKT cell functional subsets will eventually help in designing new strategies to explore the therapeutic potential of these cells for the benefit of immunocompromised patients.

\section{INKT FUNCTIONAL SUBSETS}

In contrast to conventional $\mathrm{T}$ cells, iNKT cells can acquire functional maturity in the thymus before their egress to peripheral tissues. Historically, a linear differentiation model was proposed, which postulated that CD1d-selected $\mathrm{CD} 24^{+}$stage 0 (st0) immature iNKT cells mature through sequential stages: via CD $44^{\text {low }} \mathrm{NK} 1.1^{-}$stage 1 (st1) iNKT cells characterized by IL4-producing capabilities to CD44 ${ }^{\text {high }} \mathrm{NK} 1.1^{-}$(st2) iNKT cells with IL-4- and IL-17-biased features, and finally to terminally matured CD44 ${ }^{\text {high }}$ NK1.1 $1^{+}$(st3) iNKT cells with IFN- $\gamma$-biased polarization (35). However, direct evidence of differentiation of st1 and st 2 iNKT cells into terminally matured st 3 iNKT cells was not demonstrated (36). The first evidence probing the above question on whether IL-4-producing thymic iNKT cells can give rise to IFN- $\gamma$-producing iNKT cells was addressed by Watarai et al., who demonstrated that IL-4-producing IL-17 receptor
TABLE 1 | Differential expression of surface markers and transcription factors on iNKT cell functional subsets.

\begin{tabular}{|c|c|c|c|c|}
\hline $\begin{array}{l}\text { iNKT } \\
\text { subsets }\end{array}$ & $\begin{array}{l}\text { Key } \\
\text { secreted } \\
\text { cytokines }\end{array}$ & $\begin{array}{l}\text { Signature } \\
\text { transcription } \\
\text { factors }\end{array}$ & $\begin{array}{l}\text { Surface } \\
\text { marker }\end{array}$ & References \\
\hline iNKT1 & $\begin{array}{l}\text { - IFN- } \gamma \\
\text { - TNF- } \alpha\end{array}$ & $\begin{array}{l}\text { - } \text { T-bet }^{+} \\
\text {- PLZF low }\end{array}$ & $\begin{array}{l}\text { - }{\mathrm{CD} 122^{+}}^{-} \\
\text {- } \mathrm{CXCR3^{+ }} \\
\text { - } \mathrm{L}-17 \mathrm{RB}^{-} \\
\text {- } \mathrm{CD}^{-} \mathrm{a}^{+} \\
\text {- } \mathrm{CD}_{3 \mathrm{HG}^{-}} \\
\text {- } \mathrm{ICOS}^{-} \\
\text {- } \mathrm{CD}^{+} 7^{+}\end{array}$ & $(25-28)$ \\
\hline iNKT2 & $\begin{array}{l}\text { - IL-4 } \\
\text { - IL-5 } \\
\text { - IL-13 }\end{array}$ & $\begin{array}{l}\text { - PLZFhigh } \\
\text { - GATA-3 high }\end{array}$ & $\begin{array}{l}\text { - } \mathrm{IL}^{-17 \mathrm{RB}^{+}} \\
\text {- } \mathrm{CD}^{+} \\
\text {- } \mathrm{ICOS}^{+} \\
\text {- } \mathrm{CD}_{3} \mathrm{HGG}^{\mathrm{inter}} \\
\text { - } \mathrm{CD}^{+} 7^{+}\end{array}$ & $(25-28)$ \\
\hline iNKT17 & $\begin{array}{l}\text { - IL-17 } \\
\text { - IL-22 }\end{array}$ & $\begin{array}{l}\text { - } \mathrm{ROR} \mathrm{t}^{+} \\
\text {- } \mathrm{PLZF} \text { inter }\end{array}$ & $\begin{array}{l}\text { - } \mathrm{ICOS}^{+} \\
\text {- } \mathrm{CCR6}^{+} \\
\text {- } \mathrm{CD}^{+} 03^{+} \\
\text {- } \mathrm{NRP}^{+} \\
\text {- } \mathrm{CD}^{-} \\
\text {- } \mathrm{IL}^{-} 17 \mathrm{RB}^{+} \\
\text {- } \mathrm{CD} 43 \mathrm{HG}^{+} \\
\text {- } \mathrm{CD} 138 \\
\text { - } \mathrm{LL}^{+} 23 \mathrm{R} \\
\text { - } \mathrm{CD} 27^{-}\end{array}$ & $(25-29)$ \\
\hline iNKT10 & $\begin{array}{l}\cdot \mid \mathrm{IL}-2 \\
\cdot \mathrm{IL}-10\end{array}$ & $\begin{array}{l}\text { - }{\mathrm{E} 4 \mathrm{BP} 4^{+}}^{+} \\
\text {- } \mathrm{PLZF}^{-}\end{array}$ & $\begin{array}{l}\text { - } \mathrm{PD}^{+} \\
\text {- } \mathrm{CD} 49 \mathrm{~d}^{+} \\
\text {- } \mathrm{NRP}^{+} \\
\text {- } \mathrm{CD}^{+}\end{array}$ & (27) \\
\hline $\mathrm{iNKT}_{\mathrm{FH}}$ & - IL-21 & - ${\mathrm{BCL}-6^{+}}^{+}$ & $\begin{array}{l}\text { - } \mathrm{PD}^{+} \\
\text {- } \mathrm{CXCR}^{+} \\
\text {- } \mathrm{CD}^{+}\end{array}$ & (27) \\
\hline
\end{tabular}

iNKT, invariant NKT.

B (IL-17RB) expressing thymic iNKT cells do not generate IFN- $\gamma$-producing T-bet $^{+}$thymic iNKT cells upon intrathymic transfer (25).

More recently, based on intracellular staining patterns of lineage-specific transcription factors such as T-bet, GATA-3, PLZF, and ROR $\gamma t$, Lee et al. demonstrated that there are at least three distinct iNKT functional subsets in the thymus, designated as iNKT1, iNKT2, and iNKT17, akin to the classification of classical CD4 $\mathrm{T}$ helper cell types $\left(\mathrm{T}_{\mathrm{H}} 1, \mathrm{~T}_{\mathrm{H}} 2\right.$, and $\mathrm{T}_{\mathrm{H}} 17$ cells, respectively) (26). iNKT1 cells express NK cell-related markers, are T-bet ${ }^{+}$PLZF $^{\text {low }}$, and produce mainly IFN- $\gamma$. Moreover, iNKT2 cells are GATA-3 ${ }^{\text {high }}$ PLZF ${ }^{\text {high }}$ and produce high levels of IL-4, whereas iNKT17 cells are defined as ROR $\gamma \mathrm{t}^{+}$ PLZF ${ }^{\text {intermediate }}$ and produce IL-17 upon stimulation. Thus, NKT functional subsets can be distinguished on the basis of their expression profile of characteristic surface markers and signature transcription factors (Table $\mathbf{1}$ ).

iNKT cells also can be subdivided into $\mathrm{CD}^{+}$and $\mathrm{CD}^{-}$ subsets, where both murine and human $\mathrm{CD}^{-}$subsets show $\mathrm{T}_{\mathrm{H}} 1$ biased cytokine polarization and enhanced cytotoxic activity compared with $\mathrm{CD}^{+}$counterparts (37-39). In line with this, granzyme A (Gzma) and granzyme B (Gzmb), key genes involved in NK-triggered killing, are expressed specifically on CD4- ${ }^{-}$iNKT 
cells (40). Of note, hepatic CD4- iNKT cells possess superior antitumor activity compared with thymic or splenic $\mathrm{CD}^{+}$and $\mathrm{CD}^{-}{ }^{-}$iNKT cells, suggesting that organ-specific mechanisms might dictate the functional capabilities of resident NKT cells (39). Although it remains incompletely understood whether the development of these diverse functional NKT cell subsets is related to the existence of dedicated precursor cells or is due to specific differentiation programs, a revised model, termed "lineage diversification," is proposed, which suggests thymic iNKT functional subsets represent stable distinct lineages rather than functional maturation stages $(26,30)$.

In addition to these subsets, iNKT follicular helper cells $\left(\mathrm{iNKT}_{\mathrm{FH}}\right)$ and IL-10-producing iNKT10 cell subsets were described (41-44). Although it is unclear whether iNKT $\mathrm{FH}_{\mathrm{FH}}$ cells originate from the thymus, iNKT10 cells can arise in the thymus of F108Y mice, which harbor a mutation in the TCR $\beta$-chain that results in altered iNKT TCR conformation (45). In addition to this, iNKT cells convert into IL-10-producing cells upon repeated injection with agonistic glycolipid $\alpha$-GalCer (46), which suggests iNKT cells might have some degree of sub-lineage plasticity. In regard to this, there is a report on induction of TGF- $\beta$-dependent FOXP3 $^{+}$iNKT cells in the periphery upon administration of $\alpha$-GalCer (47).

Moreover, the relative frequencies of functional subsets differ between inbred mouse strains, such as $\mathrm{C} 57 \mathrm{BL} / 6$ mice possess mostly iNKT1 cells, while BALB/c mice have a significantly larger iNKT2 cell subset. Additionally, iNKT cells are tissue resident and show unique tissue distribution patterns $(27,48)$.

\section{THYMIC SELECTION AND DIFFERENTIATION}

The development of the iNKT cell lineage proceeds in the thymus, where the precursor cells that successfully assembled their antigen receptor through recombination mediated by the recombination-activating gene (RAG) are positively selected on CD1d-expressing cortical $\mathrm{CD} 4^{+} \mathrm{CD} 8^{+}$double-positive (DP) thymocytes (49). Although the majority of iNKT cells are generated from DP thymocytes, it was recently demonstrated that a fraction of iNKT cells develops directly from the $\mathrm{CD}^{-} \mathrm{CD}^{-}$double-negative (DN) stage of thymic ontogeny, bypassing the DP stage. Fate-mapping experiments as well as conditional ablation of RAG2 at the DP stage demonstrated that a fraction of $\mathrm{CD}^{-}$iNKT cells were able to develop directly from DN-stage thymocytes without passing through the DP stage (50). This suggested a scenario in which DNstage thymocyte precursors expressing rearranged V $\alpha 14 \mathrm{~J} \alpha 18$ generated by random rearrangement events are positively selected on CD1d and develop into mature $\mathrm{CD}^{-}$iNKT cells (Figure 1).

Although the exact nature of endogenous ligands presented by CD1d responsible for positive selection of iNKT cells remains to be determined, it was recently reported that mammalian $\alpha$ linked glycosylceramides represent a candidate for an iNKT cell self-ligand in mice (6). In striking contrast to conventional T cells that undergo clonal deletion upon receiving strong signaling via
TCR-MHC interaction, iNKT cells are considered to be selected via strong TCR signals in the thymus. The evidence suggesting agonist selection of iNKT cells is based, among others, on the previously activated and/or memory phenotype of iNKT cells as well as the elevated expression levels of markers associated with TCR signaling such as Egr2 (51) and Nur77 (52) on early iNKT cells. In addition to this strong TCR signaling during selection, the development of iNKT cells requires homotypic interactions between signaling lymphocytic activation molecule family (SLAM) receptors Slamf1 (CD150) and Slamf6 (Ly108) expressed on selector DP thymocytes (53). Reporter mice for TCR signal strength revealed that iNKT cells receive TCR signals during a relatively short developmental time window exclusively at the st0 immature iNKT cell stage (52). These selection signals induce Ras- and $\mathrm{Ca}^{2+}$-dependent transcription factors Egr1 and Egr2, where Egr2 is shown to directly regulate the expression of promyelocytic leukemia zinc finger (PLZF) (51). PLZF represents a key regulator of the innate-like effector functions of iNKT cells $(54,55)$. However, there is currently no clear consensus on how PLZF is induced, as it was shown that TCR stimulation is not sufficient to induce PLZF expression on pre-selection DP thymocytes (56), suggesting other unknown signals are likely to be required for the development of PLZFexpressing innate $\mathrm{T}$ cells such as iNKT. One important factor might be the property of the positively selecting cell type, as CD4 T cells selected by MHC class II-expressing thymocytes express PLZF and show innate-like characteristics (57-59). Moreover, as PLZF expression can be detected in a subset of DN2 thymocytes (60), it is possible that those early-stage precursors expressing PLZF could differentiate later into a PLZF-expressing iNKT cells. In addition to this, premature expression of PLZF on DP thymocytes was demonstrated in $\mathrm{pT} \alpha / \mathrm{Id} 2 / \mathrm{Id} 3$-deficient mice (61), which suggests a heterogeneity within pre-selection developmental intermediates $(62,63)$.

Much less is known regarding the negative selection of NKT cells. It was reported that intrathymic injection of $\alpha$-GalCer and forced expression of CD1d on thymocytes or thymic antigenpresenting cells (APCs) such as dendritic cells (DCs) led to reduced numbers of iNKT cells (64-66). Whether negative selection shapes the iNKT cell population in normal development remains unclear.

\section{DEVELOPMENTAL TIMING OF T CELL RECEPTOR EXPRESSION}

The early thymic development of iNKT cells presumably mirrors that of conventional $\alpha \beta$ T lymphocytes, where the early multipotential bone marrow-derived progenitors differentiate through tightly regulated DN stages 1 to 4 defined based on expression of CD117, CD25, and CD44 markers $(67,68)$. Major commitment to the $\alpha \beta \mathrm{T}$ cell lineage occurs at the DN3 stage, where rearrangement of the TCR $\beta$-chain genes and subsequent beta-selection take place (69). Those DN3-stage thymocytes expressing functional pre-TCR, composed of preTCR $\alpha / \mathrm{TCR} \beta$, differentiate further into the DN4 stage to become DP thymocytes. Although it is well-accepted that rearrangement 


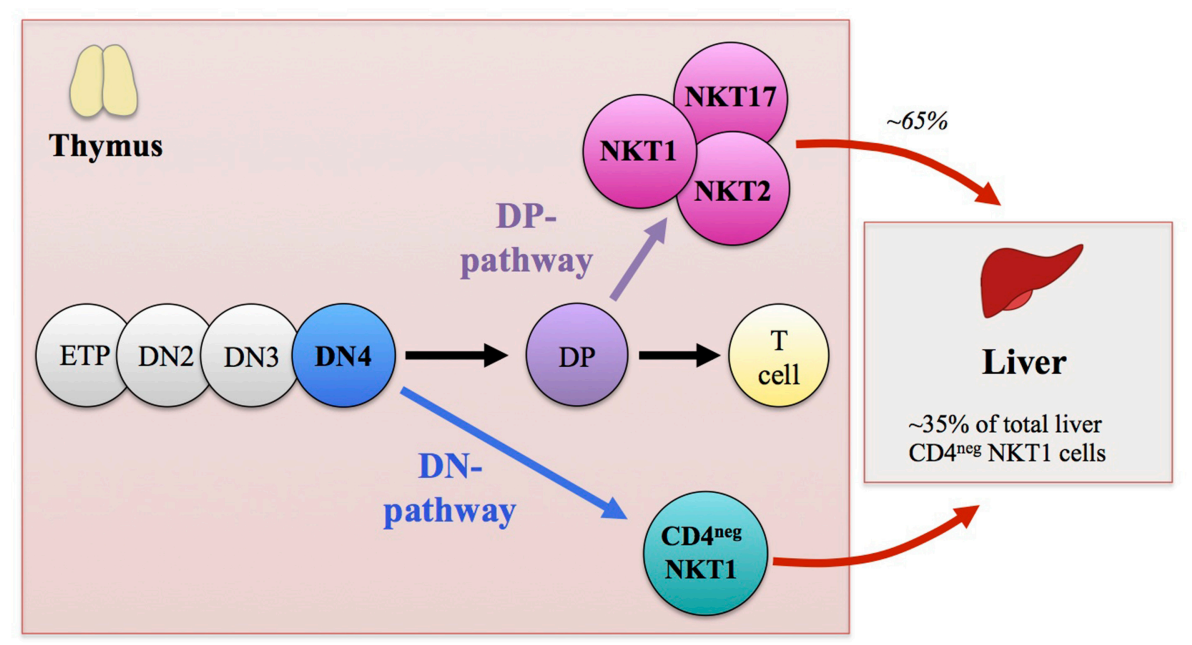

FIGURE 1 | Schematic representation illustrating the thymic development of invariant NKT (iNKT) cells. Early thymic development of iNKT cells mirrors that of $\alpha \beta$ T lymphocytes. Thymocyte precursor cells differentiate through $\mathrm{CD}^{-}{ }^{-} \mathrm{CD}^{-}{ }^{-}$double-negative (DN)1-to-DN4 stages to become CD4 ${ }^{+} \mathrm{CD} 8^{+}$double-positive (DP) thymocytes. In contrast to peptide-recognizing T cells that are selected at the DP stage of thymic ontogeny by highly polymorphic MHC class I or II molecules expressed on thymic radio-resistant stromal cells, iNKT cells are selected with glycolipid antigen-presenting monomorphic CD1d-expressing thymocytes. The majority of iNKT cells (including iNKT1, iNKT2, and iNKT17 functional subsets) derive from DP thymocyte precursors that express the invariant $\mathrm{V} \alpha 14 \mathrm{~J} \alpha 18 \mathrm{TCR} \alpha$-chain paired with a V $\beta 8 / 7 / 2$ TCR $\beta$-chain. These DP precursors commit to the iNKT cell lineage after being positively selected by CD1d-expressing cortical thymocytes. However, a fraction of CD4- iNKT cells develops directly from the DN4 stage thymocyte precursors without passing through the DP stage of thymic ontogeny. Although both the DN and DP pathways contribute to the generation of CD4- ${ }^{-}$iNKT cells, the DN pathway preferentially gives rise to IFN- $\gamma$-producing iNKT1 cells with augmented cytotoxic properties. In addition, the DN pathway generates CD4- iNKT cells with distinct peripheral distribution patterns compared with DP pathway-generated counterparts. The CD4 ${ }^{-}$iNKT cells generated by the DN pathway are found mainly in the liver, where DN thymocyte-origin CD4- iNKT cells constitute $\sim 35 \%$ of the total CD4- iNKT cells, while $\sim 65 \%$ of the total CD4- iNKT cells are generated through the DP pathway.

of the TCR $\alpha$-chain occurs at the DP stage, there are some reports demonstrating the presence of TCR $\alpha$ transcripts within DN-stage thymocytes prior to differentiation into the DP stage (70-72). In this regard, it was reported that the DN4-stage thymocytes express V $\alpha 14 \mathrm{~J} \alpha 18$ iTCR and RAG transcripts and possess iNKT cell potential in vivo (72). Furthermore, TCR sequencing experiments revealed the presence of out-of-frame Trav11Traj18 sequences, providing compelling evidence for ongoing stochastic $\mathrm{TCR} \alpha$-chain rearrangements within late $\mathrm{DN}$ stage thymocytes (50).

It seems that iNKT TCR expression during the late DN stage of thymic ontogeny plays a role in shaping the iNKT functional subset choice. Although both DN and DP pathways contribute to the generation of $\mathrm{CD}^{-}$iNKT cells, the former pathway "preferentially" gives rise to IFN- $\gamma$-producing $\mathrm{T}_{\mathrm{H}} 1$ type iNKT cells with augmented cytotoxicity, compared to their counterparts of DP cell origin (50). Of note, such "preferential" development of $\mathrm{T}_{\mathrm{H}}$ 1-type cells appears to be a general attribute of unconventional $\mathrm{T}$ cells that are generated as a result of early TCR expression at the DN stage of thymic ontogeny (73).

A potential mechanism for the "preferential" development of $\mathrm{T}_{\mathrm{H}}$ 1-biased iNKT cells might be related to the differentiation stage of precursor cells undergoing positive selection. In this context, it was shown that DN-stage thymocytes normally express the IL-7 receptor (IL-7R), downregulate its expression after differentiating into the DP stage, and then reexpress it as post-selection $\alpha \beta \mathrm{T}$ cells (74). It was reported that IL-7R determines the fate of cytotoxic effector cells via induction of Runx3, which upregulates genes associated with cytotoxic lineage cells (75). In line with this, gene expression-profiling experiments revealed that the iNKT cells of DN cell origin had elevated expression of the IL-7R and its downstream associated genes characteristic of cytotoxic cells, such as Runx3, Gzmb, and Prf1, compared to iNKT cells of DP cell origin (50).

In addition to their functional bias, NKT cells of DN cell origin had a peripheral distribution pattern different from that of NKT cells of DP cell origin. NKT cells of DN cell origin were present mainly in the liver, a result that could be explained in part by their elevated expression of genes encoding liverhoming factors. In contrast, the NKT cells of DP cell origin were present mainly in the spleen but also in mesenteric lymph nodes, lamina propria, and adipose tissues, and they had high expression of genes encoding the homing factors responsible for peripheral localization, such as CCR6, CCR7, and CCR9 (50, 76-78).

Collectively, the above results suggest that the acquisition of diverse functional characteristics by iNKT cells might be dependent on the timing of TCR expression as well as on the differentiation stage of precursor cells undergoing positive selection.

\section{T CELL RECEPTOR SIGNAL STRENGTH}

Recently, two groups reported that the TCR signal strength directs the differentiation of iNKT functional subsets (79, 
80). Both studies made use of the well-characterized SKG mouse strain, which contains a hypomorphic ZAP70 allele due to a spontaneous mutation in an $\mathrm{SH} 2$ domain. ZAP70 ( $\zeta-$ chain-associated protein kinase of $70 \mathrm{kDa}$ ) is a Syk family tyrosine kinase that is activated upon engagement of TCR and phosphorylates the linker of activated T cells (LAT) and the $\mathrm{SH} 2$ domain-containing leukocyte protein of $76 \mathrm{kDa}$ (SLP76 ), and thus is thought to play an essential role for $\mathrm{T}$ cell development (81-84). Strikingly, analyses of iNKT cells from SKG mice demonstrated that decreased TCR signaling strength leads to a predominance of NKT1 cells, whereas iNKT2 and iNKT17 cell subsets are reduced $(79,80)$. Based on the above results, it was proposed that higher TCR signals are necessary for the development of iNKT2 and iNKT17 cells, while iNKT1 cell development is relatively undisturbed in the context of reduced TCR signaling capacity $(79,80)$.

In contrast to the above, analyses of iNKT cells from the YYAA mouse strain (85), another mouse model of hypomorphic ZAP70, revealed that while the frequency of the iNKT2 subset is reduced, the proportion of iNKT17 is actually higher than that of wild-type mice and the percentage of iNKT1 cells is unchanged (80). In addition, more recently, it was shown that the iNKT1 subset is reduced in $\mathrm{CD} 247^{6 \mathrm{~F} / 6 \mathrm{~F}}$ mice, in which the TCR signaling capacity is reduced by $\sim 60 \%$ as a result of phenylalanine (F) substitution of tyrosine phosphorylation sites of the six endogenous immunoreceptor tyrosine-based activation motifs (ITAMs) of $\mathrm{CD} 3 \zeta$, an obligate signal transducer of the TCR/CD3 complex (86).

Moreover, deficiency in the TCR signaling-independent transcription factor SOX4 results in specific reduction of the iNKT1 subset (86). In Sox4-deficient thymocytes, the levels of miR181, which regulates the TCR signaling threshold of DP thymocytes (87), are diminished (86). While the iNKT cell development is impaired in miR181-deficient mice (88), residual iNKT cells in these mice show increased proportions of the iNKT2 and iNKT17 subsets at the expense of reduced frequency of the iNKT1 subset (89). The above-mentioned defects in the iNKT cell development and in the proportion of iNKT subsets seen in miR181-deficient mice are normalized upon introduction of a pre-rearranged Va14 iTCR transgene (89). Furthermore, the differentiation and functional diversification of PLZF-expressing $\gamma \delta \mathrm{NKT}$ cells occur completely unperturbed in the absence of miR181 (90). As agonist selected T cells depend on miR181 expression, this suggests that $\gamma \delta \mathrm{NKT}$ cells are not agonist selected. Nevertheless, these cells acquire PLZF expression and the ability to produce IFN- $\gamma$ (with and without miR181), and they expand in the liver in the absence of iNKT cells. These findings argue against a sole role of agonist TCR signals to govern later functional differentiation of innate-like $\mathrm{T}$ cells. It was also reported that autophagy influences the iNKT functional maturation, whereby the iNKT1 cell subset is mostly affected via regulation of the cell cycle and survival processes $(34,91,92)$. Additionally, let-7 and miR-17 contribute to iNKT subset development via post-transcriptional regulation of PLZF or TGF- $\beta$ R II expression in post-selection iNKT cells, respectively $(93,94)$.

Collectively, the current literature does not provide a clear consensus interpretation on how differential TCR signaling strength affects iNKT functional maturation into distinct subsets. Further complicating the matter, it is possible that the kinetics of acquiring TCR signals over time might be as important as the avidity or quantity of individual TCR signaling events per se (95). Sub-lineage choices might occur based on whether TCR signaling persists or ceases as the case of conventional CD4 T or CD8 T cell choice proposed by the kinetic signaling model (96). It is also possible that positive selection and sub-lineage choices are sequential but not simultaneous events. Finally, other undefined TCR-independent factors provided by the microenvironment might affect the differentiation of iNKT functional subsets, as it was reported that iNKT1, iNKT2, and iNKT17 subsets develop, albeit with subtle variations, in mouse models with the monoclonal iNKT TCR specificity $(22,97)$.

\section{CONCLUDING REMARKS}

Despite tremendous progress in the field, a number of important questions regarding the development of iNKT cell subsets remain unanswered. First, it is not completely understood why strong agonist signaling, which normally results with the clonal deletion in conventional $\mathrm{T}$ cells, culminates in the positive selection of the iNKT cell lineage. Second, how stable are these functional subsets and can they interconvert? In this context, it remains unknown what iNKT cell subsets are the precursors of $\mathrm{iNKT}_{\mathrm{FH}}$ and iNKT10 cells. Third, what are the factors that dictate homing and maintenance of iNKT cell subsets to different tissue sites? As currently there is no consensus view on the precise mechanisms driving the development of the functionally distinct iNKT sub-lineages, it is tempting to hypothesize that multiple mutually nonexclusive mechanisms might exist. A better understanding of functional differentiation mechanisms of the iNKT cell lineage could contribute in developing optimized strategies intended to exploit the unique features of iNKT cells for the benefit of patients.

\section{AUTHOR CONTRIBUTIONS}

ND wrote the first draft. ND, SB, and MS-S edited the manuscript.

\section{FUNDING}

This work was supported by the Deutsche Forschungsgemeinschaft through an SFB 1054 A02 to MS and by the Science and Technology Center Research Grant from the Mongolian National University of Medical Sciences to ND. 


\section{REFERENCES}

1. Godfrey DI, Uldrich AP, McCluskey J, Rossjohn J, Moody DB. The burgeoning family of unconventional T cells. Nat Immunol. (2015) 16:111423. doi: $10.1038 /$ ni.3298

2. Salio M, Silk JD, Jones EY, Cerundolo V. Biology of CD1and MR1-restricted T cells. Ann Rev Immunol. (2014) 32:32366. doi: 10.1146/annurev-immunol-032713-120243

3. Kinjo Y, Tupin E, Wu D, Fujio M, Garcia-Navarro R, Benhnia MR, et al. Natural killer $\mathrm{T}$ cells recognize diacylglycerol antigens from pathogenic bacteria. Nat Immunol. (2006) 7:978-86. doi: 10.1038/ni1380

4. Kinjo Y, Illarionov P, Vela JL, Pei B, Girardi E, Li X, et al. Invariant natural killer T cells recognize glycolipids from pathogenic Gram-positive bacteria. Nat Immunol. (2011) 12:966-74. doi: 10.1038/ni.2096

5. Brennan PJ, Tatituri RV, Brigl M, Kim EY, Tuli A, Sanderson JP, et al. Invariant natural killer $\mathrm{T}$ cells recognize lipid self antigen induced by microbial danger signals. Nat Immunol. (2011) 12:1202-11. doi: 10.1038/ni.2143

6. Kain L, Webb B, Anderson BL, Deng S, Holt M, Costanzo A, et al. The identification of the endogenous ligands of natural killer $\mathrm{T}$ cells reveals the presence of mammalian alpha-linked glycosylceramides. Immunity. (2014) 41:543-54. doi: 10.1016/j.immuni.2014.08.017

7. Facciotti F, Ramanjaneyulu GS, Lepore M, Sansano S, Cavallari M, Kistowska M, et al. Peroxisome-derived lipids are self antigens that stimulate invariant natural killer T cells in the thymus. Nat Immunol. (2012) 13:47480. doi: $10.1038 /$ ni.2245

8. Matsuda JL, Naidenko OV, Gapin L, Nakayama T, Taniguchi M, Wang CR, et al. Tracking the response of natural killer $\mathrm{T}$ cells to a glycolipid antigen using CD1d tetramers. J Exp Med. (2000) 192:741-54. doi: 10.1084/jem.192.5.741

9. Benlagha $\mathrm{K}$, Weiss A, Beavis A, Teyton L, Bendelac A. In vivo identification of glycolipid antigen-specific T cells using fluorescent CD1d tetramers. J Exp Med. (2000) 191:1895-903. doi: 10.1084/jem.191.11.1895

10. Cui J, Shin T, Kawano T, Sato H, Kondo E, Toura I, et al. Requirement for Valpha14 NKT cells in IL-12-mediated rejection of tumors. Science. (1997) 278:1623-6. doi: 10.1126/science.278.5343.1623

11. Chandra S, Zhao M, Budelsky A, de Mingo Pulido A, Day J, Fu Z, et al. A new mouse strain for the analysis of invariant NKT cell function. Nat Immunol. (2015) 16:799-800. doi: 10.1038/ni.3203

12. Dashtsoodol N, Shigeura T, Ozawa R, Harada M, Kojo S, Watanabe T, et al. Generation of Novel Traj18-deficient mice lacking Valpha14 natural killer T cells with an undisturbed $\mathrm{T}$ cell receptor alpha-chain repertoire. PloS ONE. (2016) 11:e0153347. doi: 10.1371/journal.pone.0153347

13. Zhang J, Bedel R, Krovi SH, Tuttle KD, Zhang B, Gross J, et al. Mutation of the Traj18 gene segment using TALENs to generate natural killer $\mathrm{T}$ cell deficient mice. Sci Rep. (2016) 6:27375. doi: 10.1038/srep27375

14. Ren Y, Sekine-Kondo E, Shibata R, Kato-Itoh M, Umino A, Yanagida A, et al. A Novel mouse model of iNKT cell-deficiency generated by CRISPR/Cas9 reveals a pathogenic role of iNKT cells in metabolic disease. Sci Rep. (2017) 7:12765. doi: 10.1038/s41598-017-12475-4

15. Chen YH, Chiu NM, Mandal M, Wang N, Wang CR. Impaired NK1+ T cell development and early IL-4 production in CD1-deficient mice. Immunity. (1997) 6:459-67. doi: 10.1016/S1074-761380289-7

16. Mendiratta SK, Martin WD, Hong S, Boesteanu A, Joyce S, Van Kaer L. CD1d1 mutant mice are deficient in natural $\mathrm{T}$ cells that promptly produce IL-4. Immunity. (1997) 6:469-77. doi: 10.1016/S1074-761380290-3

17. Smiley ST, Kaplan MH, Grusby MJ. Immunoglobulin E production in the absence of interleukin-4-secreting CD1-dependent cells. Science. (1997) 275:977-9. doi: 10.1126/science.275.5302.977

18. Taniguchi M, Koseki H, Tokuhisa T, Masuda K, Sato H, Kondo E, et al. Essential requirement of an invariant $\mathrm{V}$ alpha $14 \mathrm{~T}$ cell antigen receptor expression in the development of natural killer T cells. Proc Natl Acad Sci USA. (1996) 93:11025-8. doi: 10.1073/pnas.93.20.11025

19. Bendelac A, Hunziker RD, Lantz O. Increased interleukin 4 and immunoglobulin E production in transgenic mice overexpressing NK1 T cells. J Exp Med. (1996) 184:1285-93. doi: 10.1084/jem.184.4.1285

20. Inoue $\mathrm{K}$, Wakao $\mathrm{H}$, Ogonuki $\mathrm{N}$, Miki H, Seino K, Nambu-Wakao R, et al. Generation of cloned mice by direct nuclear transfer from natural killer T cells. Curr Biol. (2005) 15:1114-8. doi: 10.1016/j.cub.2005.05.021
21. Wakao H, Kawamoto H, Sakata S, Inoue K, Ogura A, Wakao R, et al. A novel mouse model for invariant NKT cell study. J Immunol. (2007) 179:388895. doi: 10.4049/jimmunol.179.6.3888

22. Ren Y, Dashtsoodol N, Watarai H, Koseki H, Quan C, Taniguchi M. Generation of induced pluripotent stem cell-derived mice by reprogramming of a mature NKT cell. Int Immunol. (2014) 26:551-61. doi: 10.1093/intimm/dxu057

23. Bendelac A, Savage PB, Teyton L. The biology of NKT cells. Ann Rev Immunol. (2007) 25:297-336. doi: 10.1146/annurev.immunol.25.022106.141711

24. Taniguchi M, Harada M, Kojo S, Nakayama $T$, Wakao $H$. The regulatory role of Valpha14 NKT cells in innate and acquired immune response. Ann Rev Immunol. (2003) 21:483513. doi: 10.1146/annurev.immunol.21.120601.141057

25. Watarai H, Sekine-Kondo E, Shigeura T, Motomura Y, Yasuda T, Satoh R, et al. Development and function of invariant natural killer $\mathrm{T}$ cells producing $\mathrm{T}(\mathrm{h}) 2-$ and $\mathrm{T}(\mathrm{h}) 17$-cytokines. PLoS Biol. (2012) 10:e1001255. doi: 10.1371/journal.pbio.1001255

26. Lee YJ, Holzapfel KL, Zhu J, Jameson SC, Hogquist KA. Steadystate production of IL-4 modulates immunity in mouse strains and is determined by lineage diversity of iNKT cells. Nat Immunol. (2013) 14:114654. doi: 10.1038/ni.2731

27. Crosby CM, Kronenberg M. Tissue-specific functions of invariant natural killer $\mathrm{T}$ cells. Nat Rev Immunol. (2018) 18:559-74. doi: 10.1038/s41577-018-0034-2

28. Cameron G, Godfrey DI. Differential surface phenotype and contextdependent reactivity of functionally diverse NKT cells. Immunol Cell Biol. (2018) 96:759-71. doi: 10.1111/imcb.12034

29. Dai H, Rahman A, Saxena A, Jaiswal AK, Mohamood A, Ramirez L, et al. Syndecan-1 identifies and controls the frequency of IL-17-producing naive natural killer T. (NKT17) cells in mice. Eur J Immunol. (2015) 45:304551. doi: 10.1002/eji.201545532

30. Wang $\mathrm{H}$, Hogquist KA. How lipid-specific $\mathrm{T}$ cells become effectors: the differentiation of iNKT subsets. Front Immunol. (2018) 9:1450. doi: 10.3389/fimmu.2018.01450

31. Verykokakis M, Kee BL. Transcriptional and epigenetic regulation of innate-like T lymphocyte development. Curr Opin Immunol. (2018) 51:3945. doi: 10.1016/j.coi.2018.01.006

32. Bennstein SB. Unraveling natural killer T-cells development. Front Immunol. (2017) 8:1950. doi: 10.3389/fimmu.2017.01950

33. Krovi SH, Gapin L. Invariant natural killer $\mathrm{T}$ cell subsets-more than just developmental intermediates. Front Immunol. (2018) 9:1393. doi: 10.3389/fimmu.2018.01393

34. Yang G, Driver JP, Van Kaer L. The role of autophagy in iNKT cell development. Front Immunol. (2018) 9:2653. doi: 10.3389/fimmu.2018.02653

35. Benlagha K, Wei DG, Veiga J, Teyton L, Bendelac A. Characterization of the early stages of thymic NKT cell development. J Exp Med. (2005) 202:48592. doi: 10.1084/jem.20050456

36. Benlagha K, Kyin T, Beavis A, Teyton L, Bendelac A. A thymic precursor to the NK T cell lineage. Science. (2002) 296:553-5. doi: 10.1126/science.1069017

37. Lee PT, Benlagha K, Teyton L, Bendelac A. Distinct functional lineages of human V(alpha)24 natural killer T cells. J Exp Med. (2002) 195:63741. doi: 10.1084/jem.20011908

38. Gumperz JE, Miyake S, Yamamura T, Brenner MB. Functionally distinct subsets of CD1d-restricted natural killer T cells revealed by CD1d tetramer staining. J Exp Med. (2002) 195:625-36. doi: 10.1084/jem.20011786

39. Crowe NY, Coquet JM, Berzins SP, Kyparissoudis K, Keating R, Pellicci DG, et al. Differential antitumor immunity mediated by NKT cell subsets in vivo. J Exp Med. (2005) 202:1279-88. doi: 10.1084/jem.20050953

40. Georgiev H, Ravens I, Benarafa C, Forster R, Bernhardt G. Distinct gene expression patterns correlate with developmental and functional traits of iNKT subsets. Nat Commun. (2016) 7:13116. doi: 10.1038/ncomms13116

41. Chang PP, Barral P, Fitch J, Pratama A, Ma CS, Kallies A, et al. Identification of Bcl-6-dependent follicular helper NKT cells that provide cognate help for B cell responses. Nat Immunol. (2011) 13:35-43. doi: 10.1038/ni.2166

42. King IL, Fortier A, Tighe M, Dibble J, Watts GF, Veerapen N, et al. Invariant natural killer $\mathrm{T}$ cells direct $\mathrm{B}$ cell responses to cognate lipid antigen in an IL-21-dependent manner. Nat Immunol. (2011) 13:44-50. doi: 10.1038/ ni. 2172 
43. Sag D, Krause P, Hedrick CC, Kronenberg M, Wingender G. IL-10-producing NKT10 cells are a distinct regulatory invariant NKT cell subset. J Clin Invest. (2014) 124:3725-40. doi: 10.1172/JCI72308

44. Lynch L, Michelet X, Zhang S, Brennan PJ, Moseman A, Lester C, et al. Regulatory iNKT cells lack expression of the transcription factor PLZF and control the homeostasis of T(reg) cells and macrophages in adipose tissue. Nat Immunol. (2015) 16:85-95. doi: 10.1038/ni.3047

45. Vieth JA, Das J, Ranaivoson FM, Comoletti D, Denzin LK, Sant'Angelo DB. TCRalpha-TCRbeta pairing controls recognition of CD1d and directs the development of adipose NKT cells. Nat Immunol. (2017) 18:3644. doi: 10.1038/ni.3622

46. Kojo S, Seino K, Harada M, Watarai H, Wakao H, Uchida T, et al. Induction of regulatory properties in dendritic cells by Valpha14 NKT cells. J Immunol. (2005) 175:3648-55. doi: 10.4049/jimmunol.175.6.3648

47. Monteiro M, Almeida CF, Caridade M, Ribot JC, Duarte J, Agua-Doce A, et al. Identification of regulatory Foxp3 + invariant NKT cells induced by TGF-beta. J Immunol. (2010) 185:2157-63. doi: 10.4049/jimmunol.1000359

48. Lee YJ, Wang H, Starrett GJ, Phuong V, Jameson SC, Hogquist KA. Tissuespecific distribution of iNKT cells impacts their cytokine response. Immunity. (2015) 43:566-78. doi: 10.1016/j.immuni.2015.06.025

49. Wei DG, Lee H, Park SH, Beaudoin L, Teyton L, Lehuen A, et al. Expansion and long-range differentiation of the NKT cell lineage in mice expressing CD1d exclusively on cortical thymocytes. J Exp Med. (2005) 202:23948. doi: 10.1084/jem.20050413

50. Dashtsoodol N, Shigeura T, Aihara M, Ozawa R, Kojo S, Harada M, et al. Alternative pathway for the development of Valpha14(+) NKT cells directly from CD4(-)CD8(-) thymocytes that bypasses the CD4(+)CD8(+) stage. Nat Immunol. (2017) 18:274-82. doi: 10.1038/ni.3668

51. Seiler MP, Mathew R, Liszewski MK, Spooner CJ, Barr K, Meng F, et al. Elevated and sustained expression of the transcription factors Egr1 and Egr2 controls NKT lineage differentiation in response to TCR signaling. Nat Immunol. (2012) 13:264-71. doi: 10.1038/ni.2230

52. Moran AE, Holzapfel KL, Xing Y, Cunningham NR, Maltzman JS, Punt J, et al. $\mathrm{T}$ cell receptor signal strength in Treg and iNKT cell development demonstrated by a novel fluorescent reporter mouse. J Exp Med. (2011) 208:1279-89. doi: 10.1084/jem.20110308

53. Griewank K, Borowski C, Rietdijk S, Wang N, Julien A, Wei DG, et al. Homotypic interactions mediated by Slamf1 and Slamf6 receptors control NKT cell lineage development. Immunity. (2007) 27:751-62. doi: 10.1016/j.immuni.2007.08.020

54. Kovalovsky D, Uche OU, Eladad S, Hobbs RM, Yi W, Alonzo E, et al. The BTB-zinc finger transcriptional regulator PLZF controls the development of invariant natural killer T cell effector functions. Nat Immunol. (2008) 9:1055-64. doi: 10.1038/ni.1641

55. Savage AK, Constantinides MG, Han J, Picard D, Martin E, Li B, et al. The transcription factor PLZF directs the effector program of the NKT cell lineage. Immunity. (2008) 29:391-403. doi: 10.1016/j.immuni.2008.07.011

56. Zhang S, Laouar A, Denzin LK, Sant'Angelo DB. Zbtb16. (PLZF) is stably suppressed and not inducible in non-innate $\mathrm{T}$ cells via $\mathrm{T}$ cell receptormediated signaling. Sci Rep. (2015) 5:12113. doi: 10.1038/srep12113

57. Li W, Kim MG, Gourley TS, McCarthy BP, Sant'Angelo DB, Chang CH. An alternate pathway for CD4 T cell development: thymocyte-expressed MHC class II selects a distinct T cell population. Immunity. (2005) 23:37586. doi: 10.1016/j.immuni.2005.09.002

58. Choi EY, Jung KC, Park HJ, Chung DH, Song JS, Yang SD, et al. Thymocytethymocyte interaction for efficient positive selection and maturation of CD4 T cells. Immunity. (2005) 23:387-96. doi: 10.1016/j.immuni.2005.09.005

59. Lee YJ, Jeon YK, Kang BH, Chung DH, Park CG, Shin HY, et al. Generation of PLZF+ CD4+ T cells via MHC class II-dependent thymocyte-thymocyte interaction is a physiological process in humans. J Exp Med. (2010) 207:23746. doi: 10.1084/jem.20091519

60. Alonzo ES, Sant'Angelo DB. Development of PLZF-expressing innate T cells. Curr Opin Immunol. (2011) 23:220-7. doi: 10.1016/j.coi.2010.12.016

61. Roy S, Moore AJ, Love C, Reddy A, Rajagopalan D, Dave SS, et al. Id proteins suppress E2A-driven invariant natural killer T cell development prior to TCR selection. Front Immunol. (2018) 9:42. doi: 10.3389/fimmu.2018.00042

62. Verstichel G, Vermijlen D, Martens L, Goetgeluk G, Brouwer M, Thiault $\mathrm{N}$, et al. The checkpoint for agonist selection precedes conventional selection in human thymus. Sci Immunol. (2017) 2:eaah4232. doi: 10.1126/sciimmunol.aah4232

63. Mackay LK, Minnich M, Kragten NA, Liao Y, Nota B, Seillet C, et al. Hobit and Blimp1 instruct a universal transcriptional program of tissue residency in lymphocytes. Science. (2016) 352:459-63. doi: 10.1126/science. $\operatorname{aad} 2035$

64. Schumann J, Pittoni P, Tonti E, Macdonald HR, Dellabona P, Casorati G. Targeted expression of human CD1d in transgenic mice reveals independent roles for thymocytes and thymic APCs in positive and negative selection of Valpha14i NKT cells. J Immunol. (2005) 175:730310. doi: 10.4049/jimmunol.175.11.7303

65. Chun T, Page MJ, Gapin L, Matsuda JL, Xu H, Nguyen H, et al. CD1d-expressing dendritic cells but not thymic epithelial cells can mediate negative selection of NKT cells. J Exp Med. (2003) 197:90718. doi: 10.1084/jem.20021366

66. Pellicci DG, Uldrich AP, Kyparissoudis K, Crowe NY, Brooks AG, Hammond KJ, et al. Intrathymic NKT cell development is blocked by the presence of alpha-galactosylceramide. Eur J Immunol. (2003) 33:181623. doi: 10.1002/eji.200323894

67. Porritt HE, Rumfelt LL, Tabrizifard S, Schmitt TM, Zuniga-Pflucker JC, Petrie HT. Heterogeneity among DN1 prothymocytes reveals multiple progenitors with different capacities to generate $\mathrm{T}$ cell and non-T cell lineages. Immunity. (2004) 20:735-45. doi: 10.1016/j.immuni.2004.05.004

68. Shortman K, Wu L. Early T lymphocyte progenitors. Ann Rev Immunol. (1996) 14:29-47. doi: 10.1146/annurev.immunol.14.1.29

69. von Boehmer H, Aifantis I, Azogui O, Feinberg J, Saint-Ruf C, Zober C, et al. Crucial function of the pre-T-cell receptor. (TCR) in TCR beta selection, TCR beta allelic exclusion and alpha beta versus gamma delta lineage commitment. Immunol Rev. (1998) 165:111-9. doi: 10.1111/j.1600-065X.1998. tb01234.x

70. Hernandez-Munain C, Sleckman BP, Krangel MS. A developmental switch from TCR delta enhancer to TCR alpha enhancer function during thymocyte maturation. Immunity. (1999) 10:723-33. doi: 10.1016/S1074-7613 80071-0

71. Aifantis I, Bassing CH, Garbe AI, Sawai K, Alt FW, von Boehmer H. The E delta enhancer controls the generation of CD4- CD8- alphabetaTCRexpressing $\mathrm{T}$ cells that can give rise to different lineages of alphabeta T cells. $J$ Exp Med. (2006) 203:1543-50. doi: 10.1084/jem.20051711

72. Dashtsoodol N, Watarai H, Sakata S, Taniguchi M. Identification of CD4(-)CD8(-) double-negative natural killer T cell precursors in the thymus. PloS ONE. (2008) 3:e3688. doi: 10.1371/journal.pone.0003688

73. Hendricks DW, Fink PJ. Uneven colonization of the lymphoid periphery by $\mathrm{T}$ cells that undergo early TCR \{alpha\} rearrangements. J Immunol. (2009) 182:4267-74. doi: 10.4049/jimmunol.0804180

74. McCaughtry TM, Etzensperger R, Alag A, Tai X, Kurtulus S, Park JH, et al. Conditional deletion of cytokine receptor chains reveals that IL-7 and IL15 specify CD8 cytotoxic lineage fate in the thymus. J Exp Med. (2012) 209:2263-76. doi: 10.1084/jem.20121505

75. Park JH, Adoro S, Guinter T, Erman B, Alag AS, Catalfamo M, et al. Signaling by intrathymic cytokines, not $\mathrm{T}$ cell antigen receptors, specifies CD8 lineage choice and promotes the differentiation of cytotoxic-lineage $\mathrm{T}$ cells. Nat Immunol. (2010) 11:257-64. doi: 10.1038/ni.1840

76. Crispe IN. Migration of lymphocytes into hepatic sinusoids. J Hepatol. (2012) 57:218-20. doi: 10.1016/j.jhep.2011.12.035

77. Cyster JG. Chemokines, sphingosine-1-phosphate, and cell migration in secondary lymphoid organs. Ann Rev Immunol. (2005) 23:12759. doi: 10.1146/annurev.immunol.23.021704.115628

78. Jenne CN, Enders A, Rivera R, Watson SR, Bankovich AJ, Pereira JP, et al. T-bet-dependent S1P5 expression in NK cells promotes egress from lymph nodes and bone marrow. J Exp Med. (2009) 206:246981. doi: 10.1084 /jem. 20090525

79. Zhao M, Svensson MND, Venken K, Chawla A, Liang S, Engel I, et al. Altered thymic differentiation and modulation of arthritis by invariant NKT cells expressing mutant ZAP70. Nat Commun. (2018) 9:2627. doi: 10.1038/s41467-018-05095-7

80. Tuttle KD, Krovi SH, Zhang J, Bedel R, Harmacek L, Peterson LK, et al. TCR signal strength controls thymic differentiation of iNKT cell subsets. Nat Commun. (2018) 9:2650. doi: 10.1038/s41467-018-05026-6 
81. Au-Yeung BB, Deindl S, Hsu LY, Palacios EH, Levin SE, Kuriyan J, et al. The structure, regulation, and function of ZAP-70. Immunol Rev. (2009) 228:41-57. doi: 10.1111/j.1600-065X.2008.00753.x

82. Fuller DM, Zhang W. Regulation of lymphocyte development and activation by the LAT family of adapter proteins. Immunol Rev. (2009) 232:7283. doi: 10.1111/j.1600-065X.2009.00828.x

83. Jordan MS, Koretzky GA. Coordination of receptor signaling in multiple hematopoietic cell lineages by the adaptor protein SLP-76. Cold Spring Harb Perspect Biol. (2010) 2:a002501. doi: 10.1101/cshperspect.a002501

84. Negishi I, Motoyama N, Nakayama K, Nakayama K, Senju S, Hatakeyama $\mathrm{S}$, et al. Essential role for ZAP-70 in both positive and negative selection of thymocytes. Nature. (1995) 376:435-8. doi: 10.1038/376435a0

85. Hsu LY, Tan YX, Xiao Z, Malissen M, Weiss A. A hypomorphic allele of ZAP-70 reveals a distinct thymic threshold for autoimmune disease versus autoimmune reactivity. J Exp Med. (2009) 206:252741. doi: 10.1084/jem.20082902

86. Malhotra N, Qi Y, Spidale NA, Frascoli M, Miu B, Cho O, et al. SOX4 controls invariant NKT cell differentiation by tuning TCR signaling. J Exp Med. (2018) 215:2887 doi: 10.1084/jem.20172021

87. Li QJ, Chau J, Ebert PJ, Sylvester G, Min H, Liu G, et al. miR-181a is an intrinsic modulator of T cell sensitivity and selection. Cell. (2007) 129:14761. doi: 10.1016/j.cell.2007.03.008

88. Zietara N, Lyszkiewicz M, Witzlau K, Naumann R, Hurwitz R, Langemeier $\mathrm{J}$, et al. Critical role for miR-181a/b-1 in agonist selection of invariant natural killer T cells. Proc Natl Acad Sci USA. (2013) 110:740712. doi: 10.1073/pnas.1221984110

89. Blume J, Zur Lage S, Witzlau K, Georgiev H, Weiss S, Lyszkiewicz M, et al. Overexpression of Valpha14Jalpha18 TCR promotes development of iNKT cells in the absence of miR-181a/b-1. Immunol Cell Biol. (2016) 94:7416. doi: $10.1038 /$ icb. 2016.40

90. Sandrock I, Zietara N, Lyszkiewicz M, Oberdorfer L, Witzlau K, Krueger A, et al. MicroRNA-181a/b-1 is not required for innate gammadelta NKT effector cell development. PloS ONE. (2015) 10:e0145010. doi: 10.1371/journal.pone.0145010

91. Salio M, Puleston DJ, Mathan TS, Shepherd D, Stranks AJ, Adamopoulou E, et al. Essential role for autophagy during invariant NKT cell development. Proc Natl Acad Sci USA. (2014) 111:E5678-87. doi: 10.1073/pnas.1413935112
92. Pei B, Zhao M, Miller BC, Vela JL, Bruinsma MW, Virgin HW, et al. Invariant NKT cells require autophagy to coordinate proliferation and survival signals during differentiation. J Immunol. (2015) 194:587284. doi: 10.4049/jimmunol.1402154

93. Pobezinsky LA, Etzensperger R, Jeurling S, Alag A, Kadakia T, McCaughtry TM, et al. Let-7 microRNAs target the lineage-specific transcription factor PLZF to regulate terminal NKT cell differentiation and effector function. Nat Immunol. (2015) 16:517-24. doi: 10.1038/ ni. 3146

94. Fedeli M, Riba M, Garcia Manteiga JM, Tian L, Vigano V, Rossetti G, et al. miR-17 approximately 92 family clusters control iNKT cell ontogenesis via modulation of TGF-beta signaling. Proc Natl Acad Sci USA. (2016) 113:E828695. doi: 10.1073/pnas.1612024114

95. Au-Yeung BB, Melichar HJ, Ross JO, Cheng DA, Zikherman J, Shokat $\mathrm{KM}$, et al. Quantitative and temporal requirements revealed for Zap70 catalytic activity during T cell development. Nat Immunol. (2014) 15:68794. doi: $10.1038 /$ ni.2918

96. Singer A, Adoro S, Park JH. Lineage fate and intense debate: myths, models and mechanisms of CD4- versus CD8-lineage choice. Nat Rev Immunol. (2008) 8:788-801. doi: 10.1038/nri2416

97. Clancy-Thompson E, Chen GZ, Tyler PM, Servos MM, Barisa M, Brennan PJ, et al. (iNKT) cell mice reveal a role for both tissue of origin and the TCR in development of iNKT functional subsets. J Immunol. (2017) 199:15971. doi: 10.4049/jimmunol.1700214

Conflict of Interest Statement: The authors declare that the research was conducted in the absence of any commercial or financial relationships that could be construed as a potential conflict of interest.

Copyright (c) 2019 Dashtsoodol, Bortoluzzi and Schmidt-Supprian. This is an open-access article distributed under the terms of the Creative Commons Attribution License (CC BY). The use, distribution or reproduction in other forums is permitted, provided the original author(s) and the copyright owner(s) are credited and that the original publication in this journal is cited, in accordance with accepted academic practice. No use, distribution or reproduction is permitted which does not comply with these terms. 